\title{
Medical Schools' Ophthalmology Course: An Appraisal by Ophthalmology Residents
}

\author{
Yahya Abdulrahman Al- \\ Najmi iD I \\ Ahmed Hussein Subki (iD ${ }^{2}$ \\ Nazih Suwalih Alzaidi ${ }^{3}$ \\ Nadeem Shafique Butt iD ${ }^{4}$ \\ Alaa Abdulhamid Alsammahi ${ }^{5}$ \\ Firas Mohamed Madani ${ }^{5}$ \\ Mohammed Saad Alsallum (iD ${ }^{6}$ \\ Rakan Salah Al-Harbi ${ }^{7}$ \\ Nizar Mohammed Alhibshi ${ }^{5}$ \\ 'Saggaf Eye Center, Jeddah, Saudi Arabia; \\ ${ }^{2}$ Department of Internal Medicine, King \\ Faisal Specialist Hospital and Research \\ Center, Jeddah, Saudi Arabia; \\ ${ }^{3}$ Ophthalmology Department, Prince \\ Mansour Military Hospital, At Taif, Saudi \\ Arabia; ${ }^{4}$ Department of Community \\ Medicine, King Abdulaziz University, \\ Jeddah, Saudi Arabia; ${ }^{5}$ Department of \\ Ophthalmology, King Abdulaziz \\ University Hospital, Jeddah, Saudi Arabia; \\ ${ }^{6}$ Department of Neurology, King \\ Abdulaziz Medical City, Jeddah, Saudi \\ Arabia; ${ }^{7}$ Department of Family Medicine, \\ King Fahd Armed Forces Hospital, \\ Jeddah, Saudi Arabia
}

Correspondence: Yahya Abdulrahman AlNajmi

Saggaf Eye Center, Abdullah Salman St., Al

Faiha'a Dist., P.O. Box: 31903, Jeddah,

21418, Saudi Arabia

Tel +96656484428

Email dr.alnajmi@gmail.com

Nizar Mohammed Alhibshi

Department of Ophthalmology, King

Abdulaziz University Hospital,

P.O. Box 50805, Jeddah, 21533, Saudi

Arabia

Tel +966505609950

Email alhibshi@doctor.com
Objective: To investigate the perception and satisfaction of ophthalmology residents with the currently provided ophthalmology curricula to medical students.

Methods: A cross-sectional survey involving first to fourth year ophthalmology residents $(\mathrm{N}=106)$ from all regions of Saudi Arabia was conducted between December 2018 and February 2019. An online questionnaire explored opinions about the ophthalmology course regarding three dimensions. Firstly, adequacy in covering essential parts of the specialty; secondly, improvements required; and thirdly, effectiveness. A score (0-21) was calculated, indicating the overall suitability of the ophthalmology course. In addition, factors of good overall suitability (score $\geq 10$ ) were analyzed.

Results: Regarding adequacy, respondents opined that the ophthalmology course did not reasonably cover the basic part (35.8\%), clinical part (61.3\%), common disease (26.4\%), and emergencies (39.6\%). Concerning improvements required, more than $80 \%$ of the participants expressed that the course required to be improved for all its features, including duration $(80.2 \%)$, objectives $(85.8 \%)$, content $(82.1 \%)$, organization $(83.0 \%)$, and supervision $(81.1 \%)$. As to effectiveness, half of them deemed the course unhelpful in familiarizing general practitioners with common ophthalmic diseases and emergencies. Overall, the ophthalmology course was generally deemed suitable (score $\geq 10$ ) for only $27.4 \%$ of the participants, with no differences across gender, level, or region.

Conclusion: Ophthalmology residents perceived multiple deficits in the current Saudi ophthalmology teaching course. Significant improvements in ophthalmologic curricula are required, besides coping with unprecedented technological advancement in the ophthalmological field.

Keywords: ophthalmology, course, curriculum, academic, specialty, assessment, residents, opinions

\section{Introduction}

Patients with ophthalmologic complaints represent a considerable proportion of those presenting to general practice consultants $(19 \%)$ and emergency departments $(20 \%) .{ }^{1,2}$ Some of these patients potentially present with conditions that require critical evaluation by skilled general practitioners (GPs) or junior doctors to manage and refer patients before the development of unfavorable consequences. Additionally, the exponential growth of the aged population could have been associated with growing numbers of age-related eye diseases. ${ }^{3}$ Hence, the necessity to provide adequate ophthalmologic skills and knowledge to diagnose and manage ophthalmic pathologies. To achieve this, medical schools should improve the ophthalmologic competence of medical students. 
However, the place of ophthalmology within the curricula of undergraduate medical students has been subject to controversial debates for approximately one century. ${ }^{4}$ The first descriptive report about ophthalmology teaching was published by the Council of British Ophthalmologists in $1919,{ }^{4}$ when undergraduate ophthalmology curricula were investigated regarding their duration and knowledge assessment. Nonetheless, the scientific content of the curriculum, the methods, and the teaching environment were not explored. Since then, ophthalmologic education has received little attention, and the relevant undergraduate rotations have become less significant clinically. ${ }^{5}$ Rather, the clinical skills in general practice rotations have been emphasized at the expense of specialty attachments such as ophthalmology which may have resulted in a significant gap in the ability to perform a direct ophthalmologic examination by medical students. It is, in turn, reflected as a marked deficiency in eye examination performed by GPs.

In 2006, the seminal publication of a series of recommendations regarding ophthalmologic education was published to guide medical schools on their undergraduate curricula. ${ }^{6}$ The International Council of Ophthalmology (ICO) ${ }^{6}$ emphasized the need to develop evidence-based curricula in all medical schools, and their material should be able to support the basic skills and knowledge required for examination and referral to ophthalmology. In addition, the implementation of essential teaching methods, such as lectures, case studies, clinical practice, and integration with other medical subspecialties was also recommended. These subsequently shaped reliable standards for undergraduate education and eye care in multiple medical institutions globally.

In Saudi Arabia, medical practice has undergone drastic changes concomitant with the booming economic growth during the past few decades. New colleges of medicine and multiple modern hospitals have been established in various administrative regions in the kingdom, increasing the number of medical institutions from 3 to 21 colleges between 1985 and 2011. ${ }^{7,8}$ The practice of eye care could be further influenced by the continuous expansion of modern technologies in these institutions and the applied therapeutic advances. ${ }^{9}$ Besides, approximately one in 7 undergraduate medical students aspire for an ophthalmological career, and there was considerable interest in the early academic life regarding ophthalmology-related academic practices and community service activities. ${ }^{10}$ However, receiving inadequate education before graduation may negatively influence future practice. The efficiency of ophthalmologic education in Saudi Arabia has been scarcely investigated. Rather than targeting medical students to assess their curricula, it is acceptable that ophthalmologic residents can better judge the scientific materials provided to undergraduate students. Thus, in line with the worldwide deficits in undergraduate education and the advanced skills required to handle the sophisticated equipment of eye examination effectively, we sought to investigate the perception and satisfaction of ophthalmology residents with the currently provided Saudi ophthalmology curricula to medical students.

\section{Methods \\ Design and Participants}

This cross-sectional study was conducted from December 2018 and February 2019. A nationwide electronic survey included first to fourth-year ophthalmology residents from all regions of Saudi Arabia. A convenience sampling was used to include all eligible participants during the study period. No stratification by region or level was applied. A minimum of 100 participants was acceptable as a sample size. The study was approved by the institutional review board of the bioethics committee of King Abdulaziz University, Jeddah, Saudi Arabia. We affirm that all participants provided informed consent. The study was conducted in accordance with the Declaration of Helsinki.

\section{Study Questionnaire}

An electronically administered, semi-structured questionnaire was designed for this study. It contained two parts: A) Participants' characteristics including level (R1, R2, R3, or R4), gender, nationality, university of graduation, and region; B) Assessment of ophthalmology course. Part B explored the participants' opinions about the ophthalmology course regarding three dimensions, including 1) adequacy of the course in covering essential parts of the specialty, namely basic science, clinical exposure, common diseases, and common emergencies (adequacy subscale, 4 items); 2) improvements required in content, objectives, duration, organization or supervision (improvements required subscale, 5 items); and 3) effectiveness of the course in familiarizing GPs with common diseases and common emergencies, prompting specialty choice, and providing helpful background among residents (effectiveness subscale, 4 items). 


\section{Scoring System}

Questions from Part B were formulated as a Likert-type scale, with 2 (yes; no) or 3 (no; yes to some extent; yes) answering options. In the adequacy and effectiveness subscales, answering options were "no" (score $=0)$, "yes to some extent" ( $($ core $=1)$ and "yes" ( $($ core $=2)$ ). Adequacy (score range $=0,8)$ and effectiveness (score range $=0,8$ ) subscale scores were calculated by adding up the respective item scores, with higher scores indicating better adequacy and greater effectiveness, respectively. In the improvements required subscale, a reverse scoring was used, where the answer "no" was scored as 1 and answer "yes" as 0 ; thus, a higher score (range $=0,5$ ) indicates lesser improvements required, namely more positive opinion. A total score (range $=0-21$ ) was calculated as the sum of all 3 subscale scores, where a higher score indicates better overall suitability of the ophthalmology course.

\section{Statistical methods}

Statistical analyses were performed using the Statistical Package for Social Sciences version 21.0 for Windows (SPSS Inc., Chicago, IL, USA). Descriptive statistics were used to summarize the participants' characteristics and the patterns of answers to the questionnaire's Part $\mathrm{B}$ items. The reliability of the questionnaire scale (overall suitability) and subscales (adequacy, improvements required, and effectiveness) was analyzed by calculating Cronbach's alpha. Mean, standard deviation (SD), median, and 75th centile (P75) were calculated for all four variables. Kolmogorov-Smirnov and Shapiro Wilk's tests were used to analyze the distribution of the scores as mentioned above; none of these was normally distributed. Subsequently, the overall suitability score was compared by resident's level, gender, and region using nonparametric tests, including the four scores were analyzed as categorical variables using the following cutoffs: Adequacy (poor $<4$, good $\geq 4$ ); improvements required (none [score $=0$ ], one aspect [score $=1$ ], 2+ aspects [score $\geq 2$ ]); effectiveness (poor $<4$, good $\geq 4$ ); and overall suitability (not suitable [score $<10$ ] and suitable [score $\geq 10]$ ). Chi-square test was used to compare the percentage of overall suitability, adequacy level, number of improvements required, and effectiveness level between the resident's factors. A $p$-value of $<0.05$ was considered to reject the null hypothesis.
Our study was approved by the Institutional Review Board of the King Abdulaziz University Faculty of Medicine, Jeddah, Saudi Arabia, with reference number 205-17.

\section{Results}

\section{Participants' Characteristics}

We included 106 residents, and 53.8\% were males. The majority were R1 $(33.0 \%)$ or R2 (26.4\%), and were from Central (45.3\%) and Western (28.3\%) regions (Table 1).

\section{Reliability of the Questionnaire}

The questionnaire showed high reliability with Cronbach's alpha $=0.877$. Similarly, all three subscales showed good to high reliability (Table 2 ).

\section{Assessment of Ophthalmology Course}

Figure 1 presents the patterns of answers to different scale items, as classified by aspect. Regarding adequacy, respondents opined that the ophthalmology course did not reasonably cover the basic part (35.8\%), clinical part (61.3\%), common disease (26.4\%), and emergencies (39.6\%). Regarding

Table I Participants' characteristics

\begin{tabular}{|l|l|c|c|}
\hline Parameter & Category & Frequency & Percentage \\
\hline \multirow{2}{*}{ Level } & RI & 35 & 33.0 \\
& R2 & 28 & 26.4 \\
& R3 & 22 & 20.8 \\
& R4 & 21 & 19.8 \\
\hline \multirow{2}{*}{ Gender } & Male & 57 & 53.8 \\
& Female & 49 & 46.2 \\
\hline \multirow{2}{*}{ Program region } & Central & 48 & 45.3 \\
& Western & 30 & 28.3 \\
& Eastern & 13 & 12.3 \\
& Southern & 15 & 14.2 \\
\hline
\end{tabular}

Table 2 Reliability of the Questionnaire Scale and Subscales

\begin{tabular}{|l|l|l|l|}
\hline Scale & $\begin{array}{l}\text { No. Items } \\
\text { (Score } \\
\text { Range) }\end{array}$ & $\begin{array}{l}\text { Cronbach's } \\
\text { Alpha }\end{array}$ & Comment \\
\hline $\begin{array}{l}\text { Overall } \\
\text { questionnaire } \\
\text { Adequacy } \\
\text { Improvements } \\
\text { required } \\
\text { Effectiveness }\end{array}$ & $\begin{array}{l}13(0-20) \\
5(0-8)\end{array}$ & 0.877 & High reliability \\
\hline
\end{tabular}




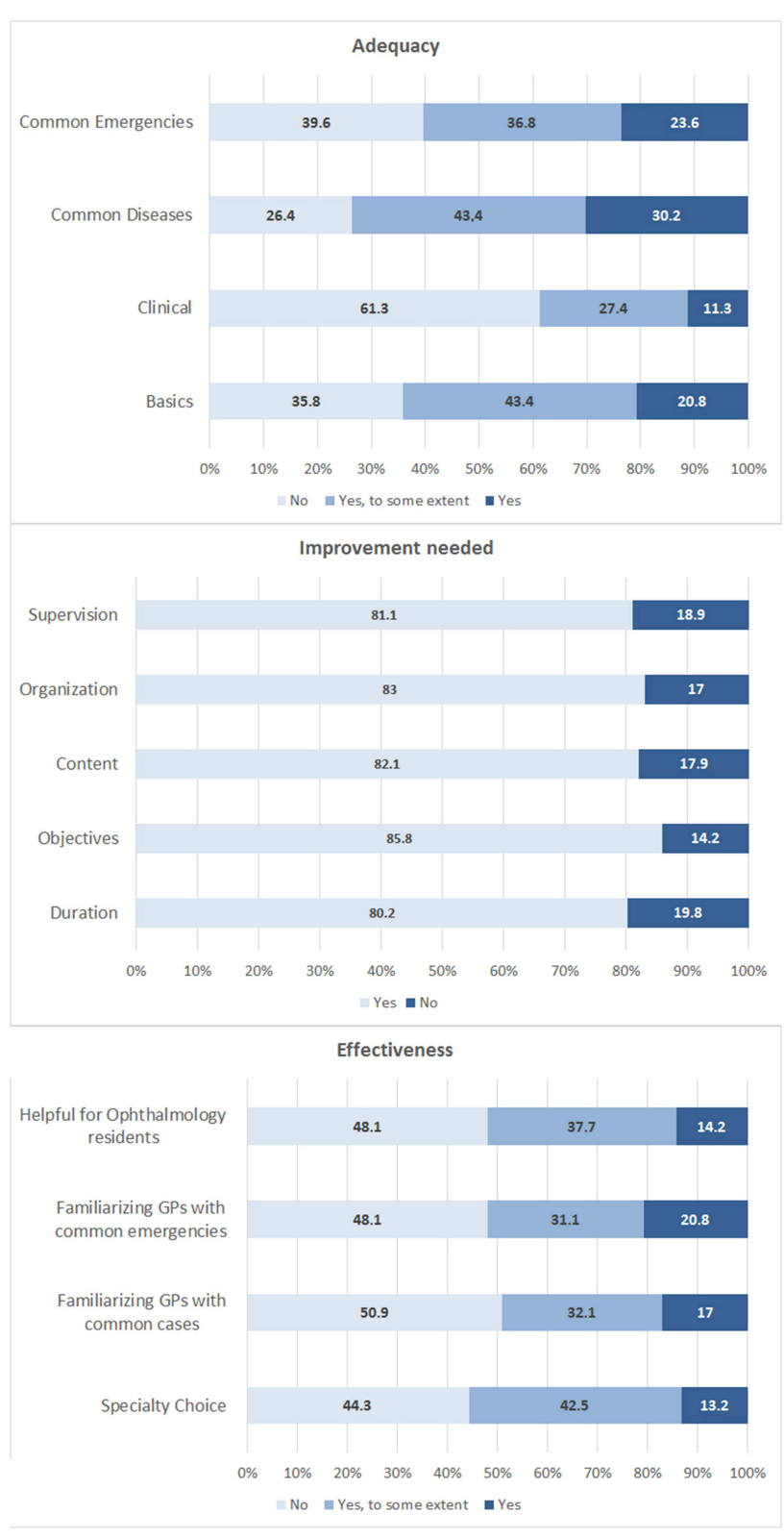

Figure I Assessment of ophthalmology course by residents: patterns of answers to the questionnaire items. Bars represent the percentage of participants who answered with the given option for the given aspect.

improvements needed, more than $80 \%$ of the participants stated that the course needed to be improved for all its features, which included duration (80.2\%), objectives $(85.8 \%)$, content $(82.1 \%)$, organization $(83.0 \%)$, and supervision $(81.1 \%)$. Regarding effectiveness, $55.7 \%$ declared that the ophthalmology course contributed partially $(42.5 \%)$ or exclusively $(13.2 \%)$ in their choice of specialty, while half of them opined that it was not helpful for residents or in familiarizing GPs with common ophthalmic diseases and emergencies.
Metrical analysis (Table 3) of the overall score showed mean $(\mathrm{SD})=6.84(5.19)$ and median $(\mathrm{P} 75)=6.00(10.00)$, which are less than half of the maximum possible score, indicating very low scores. Accordingly, the course is generally deemed suitable for only $27.4 \%$ of the participants. Similarly, the mean and median of the three subscales were less than half of the respective maximum possible scores.

\section{Participants' Factors Associated with a Course Assessment}

Females' overall scores were higher than males' (mean = 7.92 versus 5.91 , median $=8.00$ versus 5.00 , respectively), and the difference was statistically significant using the Mann-Whitney $U$-test $(\mathrm{p}=0.022)$. However, the difference in suitability rate between females (32.7\%) and males (22.8\%) was not statistically significant $(p=0.257)$. No statistically significant association of overall suitability score or suitability rate with the residents' level or region was observed (Table 4).

Analysis by aspect showed no statistically significant association of adequacy, improvements required, and effectiveness with the residents' gender, level, or region (Table 5).

\section{Discussion}

Currently, the provided undergraduate curricula in ophthalmology medical schools do not follow any national standards for teaching. By surveying ophthalmology residents, more than half of the respondents declared that ophthalmology undergraduate courses inadequately cover the required clinical aspects and do not adequately familiarize GPs with common ophthalmic diseases and emergencies. Also, the metrical analysis indicated low suitability scores since $72.6 \%$ of residents opined that the course was generally not suitable for undergraduate students. More specifically, the lowest scores were attained for the effectiveness of the course, and the majority of residents (94.3\%) have agreed that the course required at least one improvement.

Our results were in agreement with those reported in the literature, although most of the other surveys employed medical students or non-ophthalmology specialists who had been receiving an ophthalmologic education. These studies revealed multiple deficient aspects in ophthalmologic education that would consequently affect graduate students. For example, a nationwide survey in Australia showed that the taught curricula were inefficient, and there was an inadequate emphasis on ophthalmology. The 
Table 3 Assessment of Ophthalmology Course by the Residents

\begin{tabular}{|c|c|c|c|c|c|}
\hline Scale & Level & Mean (SD) & Median (P75) & $\mathbf{N}$ & $\%$ \\
\hline \multirow[t]{3}{*}{ Adequacy } & Score $(0-8)$ & $3.23(2.45)$ & $3.00(5.00)$ & & \\
\hline & Poor $(<4)$ & & & 60 & 56.6 \\
\hline & Good $(\geq 4)$ & & & 46 & 43.4 \\
\hline \multirow[t]{4}{*}{ Improvements required } & Score $(0-5)$ & $0.88(1.36)$ & $0.00(1.00)$ & & \\
\hline & None & & & 6 & 5.7 \\
\hline & One aspect & & & 19 & 17.9 \\
\hline & $2+$ aspects & & & 81 & 76.4 \\
\hline \multirow[t]{3}{*}{ Effectiveness } & Score $(0-8)$ & $2.74(2.35)$ & $2.00(5.00)$ & & \\
\hline & Poor $(<4)$ & & & 67 & 63.2 \\
\hline & Good $(\geq 4)$ & & & 39 & 36.8 \\
\hline \multirow[t]{3}{*}{ Overall suitability } & Score $(0-20)$ & $6.84(5.19)$ & $6.00(10.00)$ & & \\
\hline & Not suitable $(<10)$ & & & 77 & 72.6 \\
\hline & Suitable $(\geq 10)$ & & & 29 & 27.4 \\
\hline
\end{tabular}

Table 4 Overall Suitability of Ophthalmology Course by Residents' Gender, Level, and Region

\begin{tabular}{|c|c|c|c|c|c|c|}
\hline \multirow[t]{2}{*}{ Factor } & \multirow[t]{2}{*}{ Category } & \multicolumn{5}{|c|}{ Overall Assessment } \\
\hline & & Mean (SD) & Median (P75) & p-value* & Suitable (N, \%) & p-value ${ }^{\ddagger}$ \\
\hline \multirow[t]{4}{*}{ Level } & RI & $7.46(5.14)$ & $7.00(11.00)$ & & $10(28.6)$ & \\
\hline & R2 & $5.86(4.96)$ & $5.00(8.75)$ & & $5(I 7.9)$ & \\
\hline & R3 & $6.73(6.28)$ & $5.50(9.25)$ & & $5(22.7)$ & \\
\hline & R4 & $7.24(4.44)$ & $8.00(11.00)$ & 0.464 & $9(42.9)$ & 0.254 \\
\hline \multirow[t]{2}{*}{ Gender } & Male & $5.91(5.23)$ & $5.00(9.00)$ & & $13(22.8)$ & \\
\hline & Female & $7.92(4.98)$ & $8.00(11.50)$ & $0.022^{\dagger}$ & $16(32.7)$ & 0.257 \\
\hline \multirow[t]{4}{*}{ Program Region } & Central & $7.13(5.78)$ & $6.50(10.75)$ & & $16(33.3)$ & \\
\hline & Western & $6.60(5.15)$ & $5.00(9.75)$ & & $7(23.3)$ & \\
\hline & Eastern & $6.08(3.01)$ & $5.00(8.00)$ & & $2(15.4)$ & \\
\hline & Southern & $7.07(5.12)$ & $8.00(10.00)$ & 0.989 & $4(26.7)$ & 0.562 \\
\hline
\end{tabular}

Notes: The test used: *nonparametric tests (Mann-Whitney U-test or Kruskal-Wallis test, as applicable); ${ }^{\dagger}$ statistically significant result ( $\left.p<0.05\right) ;{ }^{\ddagger}$ Chi square test.

Table 5 Adequacy, Improvements Needed, and Effectiveness of Ophthalmology Course by Residents' Gender, Level, and Region

\begin{tabular}{|c|c|c|c|c|c|c|c|c|c|}
\hline \multirow[t]{2}{*}{ Factor } & \multirow[t]{2}{*}{ Category } & \multicolumn{2}{|c|}{ Adequacy } & \multicolumn{4}{|c|}{ Improvements Needed } & \multicolumn{2}{|c|}{ Effectiveness } \\
\hline & & Good & p-value & None & I-3 Aspects & 4-5 Aspects & p-value & Good & p-value \\
\hline \multirow[t]{4}{*}{ Level } & RI & $13(37.1)$ & & $2(5.7)$ & $6(17.1)$ & $27(77.1)$ & & 17 (48.6) & \\
\hline & R2 & $12(42.9)$ & & $2(7.1)$ & $3(10.7)$ & $23(82.1)$ & & $6(21.4)$ & \\
\hline & R3 & $10(45.5)$ & & $2(9.1)$ & $2(13.6)$ & $17(77.3)$ & & $8(36.4)$ & \\
\hline & R4 & II (52.4) & 0.732 & $0(0.0)$ & $7(33.3)$ & $14(66.7)$ & 0.426 & $8(38.1)$ & 0.176 \\
\hline \multirow[t]{2}{*}{ Gender } & Male & $21(36.8)$ & & $2(3.5)$ & II (19.3) & $44(77.2)$ & & $19(33.3)$ & \\
\hline & Female & $25(51.0)$ & 0.142 & $4(8.2)$ & $8(16.3)$ & $37(75.5)$ & 0.563 & $20(40.8)$ & 0.426 \\
\hline \multirow[t]{4}{*}{ Program Region } & Central & $24(50.0)$ & & $5(10.4)$ & $4(8.3)$ & $39(81.3)$ & & $19(39.6)$ & \\
\hline & Western & $10(33.3)$ & & $\mathrm{I}(3.3)$ & $8(26.7)$ & $21(70.0)$ & & $13(43.3)$ & \\
\hline & Eastern & $4(30.8)$ & & $0(0.0)$ & $3(23.1)$ & $10(76.9)$ & & $2(15.4)$ & \\
\hline & Southern & $8(53.3)$ & 0.316 & $0(0.0)$ & $4(26.7)$ & II (73.3) & 0.192 & 5 (33.3) & $0.34 I$ \\
\hline
\end{tabular}

Notes: Values are frequencies (percentages) of participants in the given factor category, whose opinions correspond to the given level of adequacy, improvement needed, and effectiveness. Chi-square test was used. 
medical students and junior medical officers had low confidence with basic clinical eye examinations, such as slit lamp use and direct ophthalmoscopy. ${ }^{11}$ Another crosssectional survey of United Kingdom (UK) medical schools showed significant variations in the organization and teaching methods, and their taught curricula failed to meet the ICO recommendations. ${ }^{5}$ Furthermore, in Canada, it has been found that only $35.7 \%$ of schools have implemented a mandatory ophthalmology rotation; the duration of each mainly was less than two weeks. ${ }^{12}$ Likewise, more than half of the students at New York University School of Medicine felt uncomfortable diagnosing eye emergencies, and they were less confident in testing visual acuity and using a direct ophthalmoscope. ${ }^{13}$

In the present investigation, no significant differences in suitability scores or rates were reported according to residency levels and the region of ophthalmology programs. The same applies to the subcategories of the assessment, including the adequacy and effectiveness of the program, as well as the required improvements. Indeed, this indicates nationwide consistency in the perception of ophthalmology residents, which was mainly criticizing the deficient aspects of the program. Moreover, these deficits have been consistent with the repeatedly reported negligence of ophthalmologic teaching in multiple settings, including ours. The deficiencies, as mentioned earlier in ophthalmologic teaching globally and locally, have indicated that medical students have not been adequately prepared to provide competent, high-quality, and confident eye care, regardless of the available resources.

Lack of adequate basic knowledge and clinical skills was significantly perceived by approximately two-thirds of our study residents. This might contribute to reducing the clinical competence of GPs and other specialties upon graduation. In the UK, the lack of adequate undergraduate education has led to marked deficiencies in basic ophthalmologic skills, particularly those who worked in emergency departments, ${ }^{14}$ and $63.9 \%$ of senior house officers had limited confidence in managing eye emergencies. ${ }^{15}$ Basic ophthalmologic examination, including direct ophthalmoscopy, should be effectively performed by nonspecialist clinicians, especially when access to an ophthalmologist is not possible. In particular, the findings of direct ophthalmoscopy could indicate devastating systemic changes, such as the detection of papilledema (indicating accelerated hypertension or lesions occupying the cerebral space), as well as cytomegalovirus retinitis and endocarditis, which require further invasive investigations. ${ }^{16,17}$
Identifying common preventable eye diseases and the subsequent referral of patients at early stages to eye care specialists is another crucial aspect of care, which can reduce the burden of community ophthalmological disorders. ${ }^{18}$ Therefore, there is an urgent need to make significant changes to undergraduate medical curricula to enhance patients' safety and increase the competency of future doctors.

Several proposed improvements could be considered to increase the competency of students. First, increasing the space of ophthalmology lectures to undergraduate students might support their competency and interests in such a specialty. In Canada, $\mathrm{Li}$ et $\mathrm{al}^{19}$ showed that instituting additional ophthalmology lectures to undergraduate year three has significantly increased their knowledge levels and has impacted their desire for teaching. Second, the contribution of all teaching staff to integrating basic scientific knowledge with clinical practice to small groups of students. ${ }^{20}$ Third, training methods, such as didactic lectures, case presentations, and PowerPoint presentations, may have significant effects with varying efficacy outcomes. ${ }^{21,22}$ Fourth, the timing of educational training is another essential aspect. Previous studies have shown that distributing ophthalmologic training across four years of study would presumably be more effective than singleor two-year programs. ${ }^{13,23,24}$ Finally, providing feedback during teaching sessions would be invaluable for promoting examination skills. Therefore, such multi-optional approaches should be considered in future reformations of medical schools' undergraduate ophthalmology course, to promote a more effective process of teaching and improve students' ophthalmology curriculum and practice.

The technological advances in the ophthalmology sector should be borne in mind. Innovation and research have an integrative role in outlining the upcoming aspects of ophthalmology practice both at the national and international levels. Only technically prepared professionals will cope with the continuous progress achieved in the market, while low-skilled doctors will be excluded. Suitable strategies should be readily applied to meet the inevitable technological changes. ${ }^{25}$

Our analysis selected residents because they have received adequate medical training and demonstrated high levels of clinical competency, as corroborated in a recent cross-sectional study. ${ }^{26}$ The local residency training consists of a 4-year structured program, where training curricula are divided into monthly rotations in multiple specialties. Both clinical and surgical ophthalmological 
skills are taught during the first two years and are extensively repeated in the following couple of years to support the learned skills. These programs were initially developed in 1982 as per the recommendations of a nationwide survey concerning the local etiological factors of blindness. ${ }^{27}$ Currently, residency training programs are directly supervised by the Saudi Commission for Health Specialties, and their curricula have provided cognitive and technical skills comparable to those required by the ICO. ${ }^{6,26}$

The present study has some limitations. Response bias is possible due to the cross-sectional nature of our analysis (namely, the accuracy of the obtained results and how they have truly reflected the population under study is unknown). The subjective nature of residents' judgments regarding the adequacy and effectiveness of the curricula may have been different than those really existing, by excluding student-related factors, such as the student's willingness to study ophthalmology, which would eventually change future competence and skills. Therefore, future nationwide studies which include both the residents and students are needed.

\section{Conclusion}

The present study showed multiple deficits in the teaching process of the ophthalmology course as perceived by residents. These were related to inadequate coverage of the basic and clinical skills required to manage patients by general practitioners and emergency physicians, and the lack of effective and informative materials that enable future students to be readily familiarized with common ophthalmic diseases. Lack of basic ophthalmological skills in future nonspecialist physicians may pose significant risks to patients' eyes and systemic health. Significant improvements such as increasing the number of teaching hours, applying integrated teaching methods, and implementing an adequate feedback mechanism in ophthalmologic curricula are required.

\section{Disclosure}

The authors report no conflicts of interest for this work.

\section{References}

1. Succar T, Grigg J, Beaver HA, Lee AG. A systematic review of best practices in teaching ophthalmology to medical students. Surv Ophthalmol. 2016;61(1):83-94. doi:10.1016/j.survophthal.2015.09. 001

2. Wenting SZ, Samin MM, Sanjay S, et al. A comparison of undergraduate clinical ophthalmology learning methods: smart phone television display versus slit-lamp teaching telescope. Can J Ophthalmol. 2017;52(4):385-391. doi:10.1016/j.jcjo.2016.11.032
3. Hashemi H, Khabazkhoob M, Nabovati P, et al. The prevalence of age-related eye disease in an elderly population. Ophthalmic Epidemiol. 2017;24(4):222-228. doi:10.1080/09286586.2016.1270 335

4. Byers WG. The place of ophthalmology in the undergraduate medical curriculum. Br Med J. 1922;2(3209):4-6. doi:10.1136/ bmj.2.3209.4

5. Hill S, Dennick R, Amoaku W. Present and future of the undergraduate ophthalmology curriculum: a survey of UK medical schools. Int $J$ Med Educ. 2017;8:389-395. doi:10.5116/ijme.59ac. f69b

6. International Council of Ophthalmology. Principles and guidelines of a curriculum for education of the ophthalmic specialist. Klin Monbl Augenheilkd. 2006;223(Suppl 4):S3-S48.

7. Kilduff C, Lois C. Red eyes and red-flags: improving ophthalmic assessment and referral in primary care. BMJ Open Qual. 2016;5(1): u211608. w4680.

8. World Health Organization. Blindness and vision impairment. Geneva: WHO; 2019. Available from: https://www.who.int/newsroom/fact-sheets/detail/blindness-and-visual-impairment. Accessed November 8, 2021.

9. Al-Essa RS, Al-Otaibi MD, Al-Qahtani BS, Masuadi EM, Omair A, Alkatan HM. Future ophthalmology practice pattern: a survey of Saudi Board of Ophthalmology residents. Saudi J Ophthalmol. 2019;33(1):1-6. doi:10.1016/j.sjopt.2019.01.005

10. Madani FM, Alasiri R, Howldar S, Zagzoog F, Alhibshi N. Perceptions and career expectation in ophthalmology among Saudi undergraduate medical students. Middle East Afr J Ophthalmol. 2018;25(3):142-149. doi:10.4103/meajo.MEAJO_261_17

11. Zhang HH, Hepschke JL, Shulruf B, et al. Sharpening the focus on ophthalmology teaching: perceptions of medical students and junior medical officers. Clin Exp Ophthalmol. 2018;46(9):984-993. doi:10. $1111 /$ ceo. 13342

12. Gostimir M, Sharma RA, Bhatti A. Status of Canadian undergraduate medical education in ophthalmology. Can J Ophthalmol. 2018;53 (5):474-479. doi:10.1016/j.jcjo.2017.11.015

13. Cobbs L, Tsui E, Haberman ID, et al. Student perceptions of the ophthalmology curriculum in medical school. $J$ Acad Ophthalmol. 2018;10(01):e79-e82. doi:10.1055/s-0038-1653974

14. Baylis O, Murray PI, Dayan M. Undergraduate ophthalmology education - a survey of UK medical schools. Med Teach. 2011;33 (6):468-471. doi:10.3109/0142159X.2010.540594

15. Sim D, Hussain A, Tebbal A, Daly S, Pringle E, Ionides A. National survey of the management of eye emergencies in the accident and emergency departments by senior house officers: 10 years on-has anything changed? Emerg Med J. 2008;25(2):76-77. doi:10.1136/ emj.2007.049999

16. Sergott RC. Headaches associated with papilledema. Curr Pain Headache Rep. 2012;16(4):354-358. doi:10.1007/s11916-012-0283-x

17. Yusuf IH, Salmon JF, Patel CK. Direct ophthalmoscopy should be taught to undergraduate medical students-yes. Eye (Lond). 2015;29 (8):987-989. doi:10.1038/eye.2015.90

18. Divya K, Suvetha K, Sen A, Sundar D. Needs assessment of ophthalmology education for undergraduate medical students - a study from a medical college in South India. Educ Health (Abingdon). 2017;30 (3):223-227. doi:10.4103/efh.EfH_52_16

19. Li B, Curts D, Iordanous Y, Proulx A, Sharan S. Evaluation of Canadian undergraduate ophthalmology medical education at Western University. Can J Ophthalmol. 2016;51(5):373-377. doi:10. 1016/j.jcjo.2016.04.024

20. Tsinopoulos IT, Symeonidis C, Tsaousis KT, et al. Contribution of integrated teaching in the improvement of an undergraduate ophthalmology curriculum. Adv Med Educ Pract. 2014;5:433-437.

21. Gupta RR, Lam WC. Medical students' self-confidence in performing direct ophthalmoscopy in clinical training. Can J Ophthalmol. 2006;41(2):169-174. doi:10.1139/106-004 
22. Gogate P, Deshpande M, Dharmadhikari S. Which is the best method to learn ophthalmology? Resident doctors' perspective of ophthalmology training. Indian $J$ Ophthalmol. 2008;56(5):409-412. doi:10.4103/0301-4738.42419

23. Esparaz ES, Binder SB, Borges NJ. How prepared are medical students to diagnose and manage common ocular conditions. J Educ Eval Health Prof. 2014;11:29. doi:10.3352/jeehp.2014.11.29

24. Lippa LM, Boker J, Duke A, Amin A. A novel 3-year longitudinal pilot study of medical students' acquisition and retention of screening eye examination skills. Ophthalmology. 2006;113(1):133-139. doi:10.1016/j.ophtha.2005.09.003
25. Kara-Junior N. Technology, teaching, and the future of ophthalmology and the ophthalmologist. Arq Bras Oftalmol. 2018;81(3):V-vi. doi:10.5935/0004-2749.20180036

26. AlEnezi SH, Alfawaz AM, Al Owaifeer AM, Althiabi SM, Tabbara KF. Assessment of ophthalmology residency programs in Saudi Arabia: a trainee-based survey. J Med Educ Curric Dev. 2019;6:2382120519855060. doi:10.1177/2382120519855060

27. Tabbara KF, Ross-Degnan D. Blindness in Saudi Arabia. JAMA. 1986;255(24):3378-3384. doi:10.1001/jama.1986.03370240048035

\section{Publish your work in this journal}

The International Journal of General Medicine is an international, peer-reviewed open-access journal that focuses on general and internal medicine, pathogenesis, epidemiology, diagnosis, monitoring and treatment protocols. The journal is characterized by the rapid reporting of reviews, original research and clinical studies across all disease areas. The manuscript management system is completely online and includes a very quick and fair peer-review system, which is all easy to use. Visit http://www.dovepress.com/ testimonials.php to read real quotes from published authors. 